Sport Science: Jurnal Sain Olahraga dan Pendidikan Jasmani ISSN 114-562X (Cetak), ISSN XXXX-XXXX(Online)

http://sportscience.ppj.unp.ac.id/index.php/jss/index

\title{
Pengaruh Latihan Jogging Dengan Treadmill Terhadap Denyut Nadi Istirahat Pada Ibu-ibu Anggota Fitness Centre Yayasan Indonesiaal 18 Kata)
}

\author{
Resmita Sulastri ${ }^{1}$, Sari Mariati ${ }^{2}$, Syamsuar $^{3}$ \\ ${ }^{123}$ Fakultas Ilmu Keolahragaan, Universitas Negeri Padang, Indonesia. \\ E-mail: resmita@yahoo.com ${ }^{1}$, sarimariatimpd@gmail.com ${ }^{2}$, syamsuar@fik.unp.ac.id ${ }^{3}$
}

\begin{abstract}
Abstrak
Latihan jogging dengan treadmill merupakan salah satu komponen kesegaran jasmani yang mencapai zona latihan dengan intensitas 70\% - 85\% dari denyut nadi maksimal, durasi $30-40$ menit dan frekuensi latihan 3 kali dalam seminggu. Penelitian ini bertujuan untuk mengetahui pengaruh jogging dengan treadmill terhadap denyut nadi istirahat pada ibu-ibu anggota fitness centre Yayasan Jantung Indonesia Cabang Utama Sumatera Barat.

Jenis penelitian yang digunakan adalah eksperimen semu (quasi eksperimen). Subjek dalam penelitian ini adalah ibu-ibu anggota fitness centre Yayasan Jantung Indonesia Cabang Utama Sumatera Barat yang berjumlah 15 orang, karena jumlah populasi relative sedikit maka seluruh populasi dijadikan sampel dengan menggunakan teknik total sampling. Variabel dalam penelitian ini adalah denyut nadi istirahat yang dihitung dalam satu menit. Teknik pengambilan dan pengumpulan data dilakukan dalam bentuk tes yang diambil tes awal dan tes akhir. Pengambilan tes awal diambil sebelum diberikan perlakuan atau sebelum diberikan bentuk latihan melalui program latihan yang telah dipersiapkan. Setelah dilakukan latihan sebanyak 16 kali pertemuan selama tiga kali dalam seminggu, maka diambil kembali tes akhir. Dari data kedua tes tersebut dilihat apakah ada pengaruh latihan jogging dengan treadmill terhadap denyut nadi istirahat pada ibu-ibu anggota fitness centre Yayasan Jantung Indonesia Cabang Utama Sumatera Barat.

Hipotesis yang diajukan dalam penelitian ini adalah terdapat pengaruh latihan jogging dengan treadmill terhadap denyut nadi istirahat pada ibu-ibu anggota fitness centre Yayasan Jantung Indonesia Cabang Utama Sumatera Barat. Berdasarkan analisis data dengan menggunakan Uji T-tes diperoleh nilai denyut nadi istirahat thitung 6,8 nilai lebih besar dibandingkan nilai yang ada pada ttabel 2,178 sehingga dapat disimpulkan bahwa terdapat pengaruh latihan jogging dengan treadmill terhadap denyut nadi istirahat pada ibu-ibu anggota fitness centre Yayasan Jantung Indonesia Cabang Utama Sumatera Barat.
\end{abstract}

Kata Kunci: Latihan jogging, treadmill, denyut nadi istirahat,

\begin{abstract}
Jogging exercise with a treadmill is one component of physical fitness that reaches the training zone with an intensity of 70\% - 85\% of the maximum pulse, duration of 30-40 minutes and frequency of exercise 3 times a week. This study aims to determine the effect of jogging with a treadmill on resting pulses in women members of the fitness center of the Indonesian Heart Foundation, Main Branch of West Sumatra.

This type of research used is quasi-experimental (quasi experiment). The subjects in this study were 15 members of the fitness center of the Indonesian Heart Foundation in the Main Branch of West Sumatra, because the population was relatively small so the entire population was sampled using total sampling techniques. The variable in this study is the resting pulse rate which is calculated in one minute. Data collection and collection techniques are carried out in the form of tests that are taken preliminary tests and final tests. Taking the initial test is taken before given treatment or before
\end{abstract}




\section{Sport Science: Jurnal Sain Olahraga dan Pendidikan Jasmani ISSN 114-562X (Cetak), ISSN XXXX-XXXX(Online) http://sportscience.ppj.unp.ac.id/index.php/jss/index}

given the form of exercise through a training program that has been prepared. After 16 sessions of exercise three times a week, the final test is taken again. From the data of the two tests, it was seen whether there was an effect of jogging exercise with a treadmill on resting pulses in women members of the Fitness Center of the Indonesian Heart Foundation, Main Branch of West Sumatra.

The hypothesis proposed in this study is that there is an effect of jogging exercise with a treadmill on resting pulses in women members of the fitness center of the Indonesian Heart Foundation, Main Branch of West Sumatra. Based on data analysis using the T-test, the resting pulse rate of 6.8 is greater than the value of the table 2.178 so that it can be concluded that there is an effect of jogging exercise with treadmill on resting pulse rate at the mothers of Foundation Fitness Center members. Heart of Indonesia Main Branch of West Sumatra.

Keywords: Jogging exercise, treadmill, resting pulse

\section{PENDAHULUAN}

Latihan merupakan kegiatan yang dilakukan secara sistematis, terprogramkan, terencana, teratur dan memiliki tujuan terhadap peningkatan kualitas individu (prestasi). Secara fisiologis latihan memberikan pengaruh terhadap kemampuan kondisi fisik sehingga dapat meningkatkan keterampilan. Selanjutnya di Sumatera Barat jumlah penderita penyakit jantung makin meningkat dari waktu ke waktu. Dalam rangka ikut serta menciptakan manusia Indonesia yang sehat, sejahtera dan terhindar dari penyakit jantung dan pembuluh darah, serta menunjang program pemerintah dalam memasyarakatkan olahraga dan mengolahragakan masyarakat, Yayasan Jantung Indonesia Cabang Utama Sumatera Barat telah melaksanakan berbagai kegiatan promotif prefentif

Jogging adalah salah satu bentuk olahraga yang dilakukan dengan cara berjalan atau lari-lari kecil, dengan memiliki frekuensi untuk meningkatkan kebugaran dengan latihan jogging diperlukan latihan tiga kali seminggu, intensitas latihan diukur dengan kenaikkan detak jantung yaitu $70 \%-85 \%$, serta lama latihan jogging yang diperlukan yaitu 30-40 menit. Denyut nadi maksimal dapat ditentukan dengan prediksi dan pengukuran yaitu 220 dikurangi usia dari denyut nadi maksimal. Menentukan denyut nadi maksimal melalui prediksi sangat bermanfaat untuk menentukan intensitas latihan (Training Zone) yang bertujuan untuk latihan yang bersifat kebugaran.

Latihan akan merangsang meningkatnya heart rate, peningkatan ini naik secara linear sesuai dengan peningkatan intensitas latihan. Meningkatnya kemampuan jantung untuk memompakan darah keseluruh tubuh dipengaruhi oleh berbagai faktor, yang faktor tersebut dapat berupa perubahan anatomis, fisiologis, atau yang terjadi akibat latihan. Otot jantung secara normal berkontraksi dengan urutan teratur dimulai dari kontraksi atrial (atrial systole) kemudian di ikuti oleh kontraksi ventrikel (ventrikel systole). Sedangkan atrium dan ventrikel mengalami relaksasi disebut diastole.

Volume darah yang dipompakan oleh jantung dapat di ketahui melalui isi sekuncup (stroke volume) dan curah jantung (cardiac output) volume stroke, volume dalam keadaan istirahat dan latihan maksimal orang yang terlatih lebihbesar dari orang yang tidak terlatih, sedangkan volume curah jantung dalam keadaan istirahat sama antara yang terlatih dengan yang tidak terlatih, tetapi pada latihan maksimal yang terlatih jauh lebih besar dibadingkan dengan yang tidak terlatih. Frekuensi denyut nadi dapat dijadikan sebagai parameter dalam menentukan intensitas latihan aerobik dan anaerobik.

Jadi berdasarkan hasil pengamatan penulis dapatkan di Fitness Centre Yayasan Jantung Indonesia dengan melihat program latihan yang diberikan kepada anggota selama ini, bahwa terlihat masih tingginya denyut nadi istirahat anggota Fitness Centre Yayasan Jantung Indonesia Cabang Sumatera Barat, anggota fitness ini umunya berusia 25-55 tahun dan pria berusia 30-60 tahun.

Parameter fisiologis yang mencerminkan kemampuan kerja jantung adalah denyut nadi karena akan meningkatkan secara linear sesuai peningkatan intensitas latihan, maka latihan dilakukan secara 
Sport Science: Jurnal Sain Olahraga dan Pendidikan Jasmani ISSN 114-562X (Cetak), ISSN XXXX-XXXX(Online)

http://sportscience.ppj.unp.ac.id/index.php/jss/index

terus menerus dengan teratur sampai pada batas kemampuan maksimal. Pada saat sekarang ini, banyak masalah yang mengakibatkan tingginya denyut nadi istirahat pada ibu-ibu anggota Fitness Centre Yayasan Jantung Indonesia Cabang Sumatera Barat. Tingginya denyut nadi istirahat ini disebabkan karena masalah obesitas atau kelebihan berat badan, faktor gaya hidup yang kurang baik, tidak teraturnya dalam melakukan latihan jogging dengan treadmill yang telah diprogramkan, serta pelaksanaan latihan dan keseriusan latihan sangat kurang.

Pada kenyataannya hal yang terlihat pada ibu-ibu anggota fitness centre Yayasan Jantung Indonesia Cabang Utama Sumatera Barat adalah kurangnya keseriusan dalam melakukan latihan jogging dengan treadmill dan latihan yang diberikan itu tidak dilaksanakan dengan teratur, mereka beranggapan bahwa latihan itu tidak mempunyai pengaruhi sama sekali. Peneliti ingin meneliti sejauh mana pengaruh latihan jogging dengan treadmill terhadap denyut nadi istirahat pada anggota fitness centre Yayasan Jantung Indonesia Cabang Sumatera Barat.

\section{METODE (15\%)}

Dalam penelitian ini, penulis menggunakan metode quasi eksperimen. Metode ini digunakan atas dasar pertimbangan bahwa sifat dari penelitian yang dilakukan adalah suatu proses yang dicobakan dalam bentuk latihan. Di samping itu, ingin meneliti pengaruh dari variabel-variabel yang diselidiki terhadap suatu kelompok untuk memperoleh hasil. Maka terlihat bahwa eksperimen merupakan penelitian yang logis dan sistematis, dimaksudkan untuk meneliti pengaruh variabel yang diselidiki guna mendapatkan suatu hasil yang di uji cobakan, sehingga masalah yang dikemukakan dapat terjawab. Rancangan penelitian dilakukan selama 1, 5 bulan dengan tempat penelitian di Fitness Center Yayasan Jantung Indonesia Cabang Sumatera Barat.

Penelitian ini dilakukan di Fitness Centre Yayasan Jantung Indonesia Cabang Utama Sumatera Barat dan waktu pelaksanaan penelitian dilaksanakan pada tanggal 12 Juni sampai dengan tanggal 22 Juli 2010. Populasi adalah keseluruhan subjek penelitian (Arikunto, 1998:115). Populasi pada penelitian ini adalah anggota ibu-ibu yang mengalami tingginya denyut nadi istirahat di Fitness Centre Yayasan Jantung Indonesia Cabang Utama Sumatera Barat yang berjumlah 15 orang.

Berpedoman pada jumlah populasi di atas, maka pengambilan sampel ditetapkan dengan menggunakan teknik total sampling, dimana sampel yang diambil secara keseluruhan anggota Ibu-ibu Fittnes Center Yayasan Jantung Indonesia Cabang Sumatera Barat, yang berjumlah 15 orang.

Sesuai dengan jenis data yang diperlukan dalam penelitian ini maka yang menjadi sumber data dalam penelitian ini adalah anggota fitness ibu-ibu di Yayasan Jantung Indonesia Cabang Utama Sumatera Barat. Data dalam penelitian ini bersumber dari usia, tinggi badan, dan berat badan. Data diambil sebelum dan sesudah diberikan perlakuan selama kegiatan latihan jogging dengan treadmill, yang dilaksanakan berdasarkan program latihan yang telah dibuat.

\begin{tabular}{|c|c|c|c|c|c|}
\hline No & Hari & $\begin{array}{c}\text { Waktu } \\
\text { Penelitian }\end{array}$ & $\begin{array}{r}\text { Lama } \\
\text { Latiha }\end{array}$ & & Keterangan \\
\hline 1 & Senin & 08.00-21.00 & $\begin{array}{l}\text { - Minggu } \\
\text { selama } \\
\text { menit }\end{array}$ & $\begin{array}{r}1,2 \\
30\end{array}$ & $\begin{array}{l}5 \text { menit pemanasan, } 20 \text { menit } \\
\text { latihan jogging dan pemulihan } 5 \\
\text { menit, dalam } 2 \text { minggu pertama } \\
\text { dengan intensitas latihan } 75 \% \\
\text { dari DNM. }\end{array}$ \\
\hline 3 & Jum'at & 08.00-21.00 & $\begin{array}{l}\text { - Minggu } \\
\text { selama } \\
\text { menit }\end{array}$ & $\begin{array}{r}3,4 \\
35\end{array}$ & $\begin{array}{l}5 \text { menit pemanasan, } 25 \text { menit } \\
\text { latihan jogging dan pemulihan } 5 \\
\text { menit dalam } 2 \text { minggu kedua } \\
\text { dengan }\end{array}$ \\
\hline
\end{tabular}




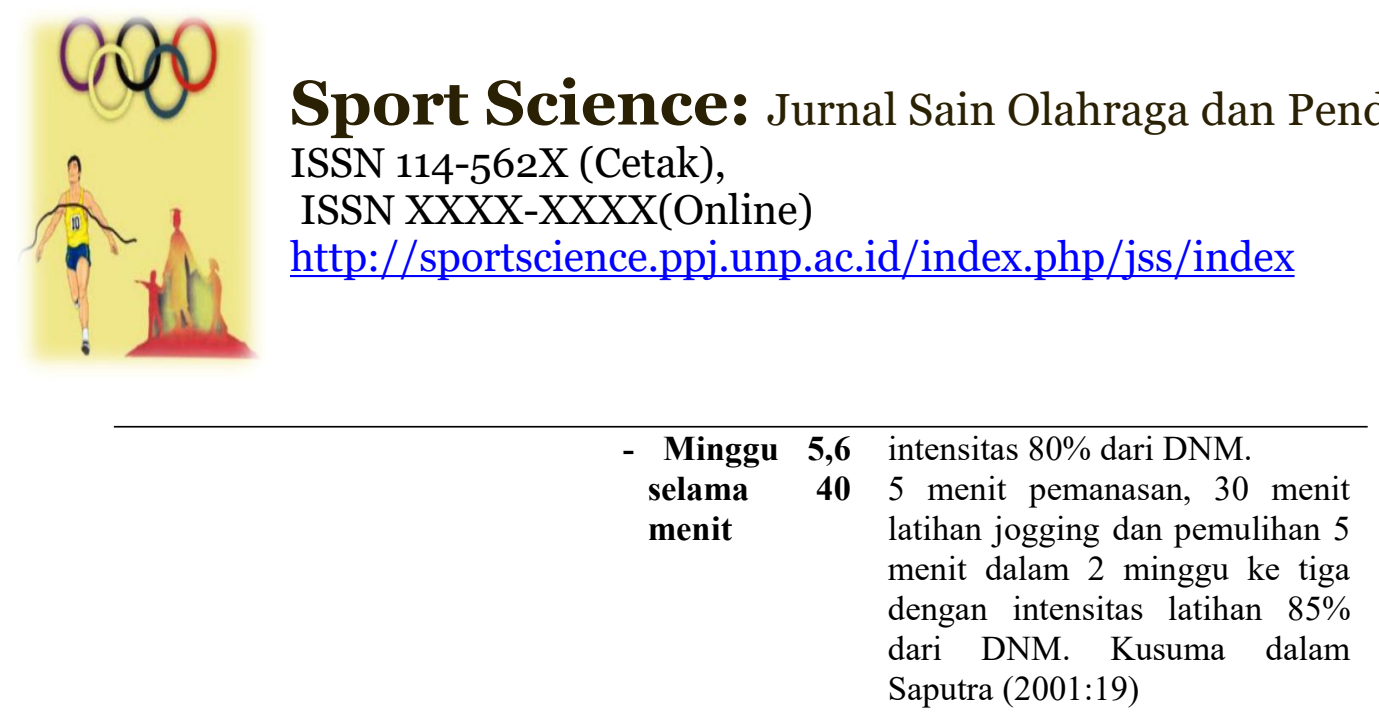

Dari uraian tabel diatas bahwa jadwal program latihan jogging dilaksanakan tiga kali dalam seminggu. Pelaksanaan latihan ini dilakukan hari senin, rabu, dan jum'at. Sedangkan waktu penelitiannya dimulai dari pagi jam 08.00 sampai dengan 12 siang, sore jam 3 sampai jam 6 dan pada waktu malamnya dari jam 7 sampai dengan 9 malam. Lama latihan ini antara 20 sampai 30 menit, dengan kecepatan yang konstan sehingga bisa mencapai zona latihan.

\section{Teknik Pengumpulan Data} akhir.

Untuk mendapatkan data dalam penelitian ini, maka dilakukan data tes yaitu tes awal dan tes

1. Tes Awal

Tes awal yaitu melakukan tes terhadap denyut nadi istirahat pada anggota fitness Centre Yayasan Jantung Indonesia Cabang Utama Sumatera Barat yang dilakukan sebelum diberikan latihan. Pengukuran denyut nadi ini dilakukan secara palpasi.

2. Tes Akhir

Tes akhir yaitu tes yang dilkukan setelah diberikan latihan. Dalam pengambilan tes akhir ini sampel telah melalui proses latihan jogging dengan treadmill selama lebih kurang enam minggu dari latihan rutin yang dilakukan 3 kali dalam satu minggu, baru diambil tes akhir. Bentuk tes akhir ini yaitu pengukuran denyut nadi istirahat.

3. Instrumentasi

Data hasil latihan jogging dengan treadmill diperoleh dengan menggunakan palpasi, ini bertujuan untuk mengukur denyut nadi istirahat.

Sebelum tes dilakukan terlebih dahulu dipersiapkan langkah-langkah, alat-alat pengumpulan data, program latihan, pelaksanaan tes serta hal-hal yang berhubungan dengan pengumpulan dan pengukuran data.

a. Alat-alat latihan guna pengumpulan data

1) Blangko tes untuk mencatat tes awal dan tes akhir (pre-test-post test).

2) 4 treadmill

3) Stop watch

4) Pulpen

b. Petugas pelaksanaan tes

Didalam pelaksanaan tes, pengambilan data dilakukan oleh tiga orang penilai yaitu instruktur, pembantu pencatat data, dan pelaksanaan tes, yaitu:

1. Instruktur

- Padli S.Si

2. Pembantu pencatat

- Rahayu Ningsih

3. Pelaksanaan tes

- Resmita Sulastri 


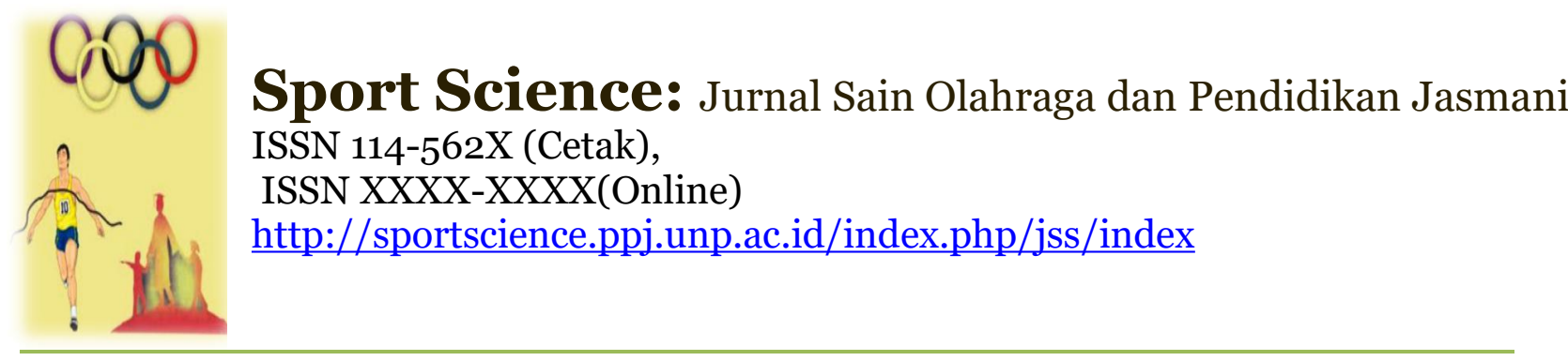

c. Pelaksanaan tes

Denyut nadi istirahat

Untuk pelaksanaan pengukuran denyut nadi istirahat langkah-langkah yang harus dilakukan adalah :

1. Sampel harus dalam keadaan rileks, kemudian sampel diberikan waktu istirahat selama 5 - 10 menit sebelum melakukan latihan jogging.

2. Setelah istirahat, denyut nadi sampel diukur dengan cara dua ujung jari kanan diletakkan pada arteri radialis sampel. Kemudian menghitung frekuensi nadi selama 10 detik dikalikan 6 dengan menggunakan stop watch.

3. Kemudian mencatat beberapa jumlah nadi sampel yang telah diukur tadi.

Sesuai dengan tujuan seta hipotesis dalam penelitian yang diajukan ini, maka pengujian data yang sudah diperoleh akan dianalisa melalui teknik yang sesuai dengan jenis serta tujuan penelitian yaitu akan dianalisis dengan menggunakan statistic deskriptif untuk melihat perbedaan mean, maka rumus yang digunakan adalah sebagai berikut :

$$
\mathrm{t}=\frac{\left(\overline{\mathrm{X}}_{1}-\bar{X}_{2}\right.}{\sqrt{\frac{\sum \mathrm{D}^{2}-\frac{\left(\sum \mathrm{D}^{2}\right.}{\mathrm{n}}}{\mathrm{n}(\mathrm{n}-1)}}}
$$

Sumber: Sudjana (1992: 244)

\section{HASIL DAN PEMBAHASAN \\ Hasil Penelitian}

Sebelum data diolah dengan formula yang telah ditentukan terlebih dahulu dilakukan verifikasi terhadap data yang terkumpul dari sampel. Hal ini perlu dilakukan karena data yang tidak memenuhi persyaratan tidak dapat diolah. Dengan pengontrolan yang cukup ketat terhadap sampel, maka dari 15 sampel penelitian ini hanya 13 orang yang mengikuti tes awal dan tes akhir, karena 1 orang tidak hadir lagi dan 1 orang lagi tidak lengkap kehadirannya. Jadi data yang diolah berjumlah 13 orang yaitu sampel yang mengikuti latihan jogging dengan treadmill yang dilaksanakan sebanyak 16 kali latihan dan ditambah dengan pengambilan tes awal dan tes akhir.

Berdasarkan penelitian yang dilakukan, maka diperoleh data dari hasil tes awal dan tes akhir. Data tes awal dan data tes akhir yang diperoleh merupakan hasil melakukan latihan jogging dengan pengambilan denyut nadi istirahat. Untuk mendapat hasil dari tes diperoleh dengan cara memberikan perlakuan kepada sampel, tes ini dilakukan secara kelompok. Hasil tes ini adalah denyut nadi istirahat yang dilakukan sebelum perlakuan (tes awal) dan sesudah perlakuan (tes akhir). Dalam melakukan tes, peneliti dibantu oleh satu pencatat data. Sebelum tes ini dilakukan oleh masing-masing sampel terlebih dahulu pelaksanaan tes menjelaskan dan memberikan pemahaman dari tujuan penelitian ini oleh peneliti, agar nantinya sampel tidak ragu dalam melakukan tes.

Berikut ini akan di paparkan tentang deskripsi dari hasil tes yang dilakukan selama eksperimen (hasil tes akhir):

1. Data pre test ( data tes awal latihan ) denyut nadi istirahat.

Variael denyut nadi istirahat diuk'r donģan menghitung jumlah denyut nadi dalam satu menit (15 detik x 4). Hasil penguk 43 rsebut dari 13 sampel di dapat skor tertinggi 84 dan skor terendah 72. Distribusi skor menghasilkan rata-rata (mean) 78,1, standar deviasi 3,86 dan mode 80 .

2. Data post tes (akhir latihan) denyut nadi istirahat. 
Dari 13 orang sampel didapatkan skor tertinggi 80 dan skor terendah 60, distribusi skor menghasilkan rata-rata (mean) 71,07, standar 6,56 dan mode 72 .

Hasil Denyut Nadi Istirahat Tes Awal dan Tes Akhir dalam analisis terhadap tes awal pada denyut nadi istirahat menunjukkan hasil yaitu nilai tertinggi 84 dan nilai terendah 72 dengan rata-rata 78,1 dan standar deviasi 3,86. Selanjutnya untuk tes akhir menunjukkan hasil untuk nilai tertinggi 80 dan nilai terendah 60 dengan rata-rata 71,07 dan standar deviasi 6,56, sehingga terdapat perbedaan rata-rata yang cukup berarti antara tes awal dengan tes akhir.

Berdasarkan analisis di atas maka dapat disimpulkan bahwa antara tes awal dan tes akhir yang dilakukan pada pengambilan denyut nadi istirahat terdapatnya penurunan denyut nadi istirahat. Penurunan atau perbedaan ini di dapat setelah perlakuan dan latihan yang diberikan melalui latihan jogging dengan treadmill.

Dari uji normalitas yang dilakukan terhadap tes awal dan tes akhir, yang dilakukan untuk uji normalitas adalah hasil perbedaan antara tes awal dan tes akhir maka didapat harga Lo (nilai tertinggi) uji normalitas yang dibandingkan dengan Lt (nilai tabel) pada tabel lilliefors dengan taraf signifikan $\alpha$ 0,05 seperti tabel dibawah ini.

\begin{tabular}{lccc}
\multicolumn{4}{c}{ Tabel Uji Normalitas dengan lilliefors } \\
\hline \multicolumn{1}{c}{ Sampel/Perlakuan } & Subjek & Lo & Lt \\
\hline Denyut nadi istirahat awal & 13 & 0,1669 & 0,234 \\
Denyut nadi istirahat akhir & 13 & 0,1366 & 0,234 \\
\hline
\end{tabular}

Dari perhitungan antara beda tes untuk denyut nadi istirahat awal dan denyut nadi istirahat akhir diperoleh Lo $<$ Lt, sehingga dapat disimpulkan bahwa data kedua populasi berdistribusi normal. Hipotesis yang diajukan dalam penelitian ini diterima kebenarannya atau tidak, maka dilakukan pengujian data dengan memakai Uji " $t$ ". Hipotesis yang diajukan dalam penelitian adalah terdapat pengaruh latihan jogging dengan treadmill terhadap denyut nadi istirahat pada ibu-ibu anggota fitness centre Yayasan Jantung Indonesia Cabang Utama Sumatera Barat.

Hasil analisis yang melihat perbedaan antara tes awal dengan tes akhir sebesar 6,8 dimana nilai lebih besar dibandingkan nilai ttabel 2,178 dengan $\alpha$ 0,05 dengan derajat kebebasan $n-1$. Maka terdapat pengaruh yang berarti antara denyut nadi istirahat dengan latihan jogging dengan treadmill. Dengan demikian Ho diterima karena thitung $>$ ttabel. Hipotesis yang diajukan diterima.

\section{Pembahasan}

Berdasarkan kepada hasil analisis data penelitian bahwa latihan jogging dengan treadmill yang dilakukan selama 16 kali pertemuan ternyata berpengaruh secara signifikan terhadap denyut nadi istirahat. Hali ini terbukti dengan hasil pengukuran yang diolah secara manual dengan uji T-tes. Dari hasil analisis yang dilakukan terdapat perbedaan, dalam arti adanya peningkatan angka rata-rata dimana rata-rata dari tes akhir denyut nadi istirahat lebih kecil dari tes awal yaitu rata-rata tes awal sebesar 78,1 dan rata-rata tes akhir sebesar 71,07.

Denyut nadi dalam keadaan istirahat biasanya berdenyut lebih lambat, hal ini menyebabkan lebih panjangnya waktu istirahat jantung sehingga jantung memompa darah lebih banyak. Salah satu komponen yang dapat memberikan petunjuk tentang hal tersebut adalah denyut nadi yang merupakan manifestasi dari kontraksi otot jantung. Jadi uraian di atas dapat disimpulkan bahwa seseorang dengan denyut nadi istirahat yang rendah relative lebih bugar dari pada mereka yang denyut nadinya tinggi. Menurut Cooper dalam Bafirman (2006:67) "Denyut nadi istirahat rendah yaitu dimana jantung dapat meangawetkan energi sekurangnya 1.500 denyutan perhari".

Jadi pada hasil analisis keseluruhan yang dilakukan, diperoleh suatu gambaran bahwa hipotesis yang dikemukakan dalam penelitian ini diterima kebenarannya yaitu terdapat pengaruh latihan jogging dengan treadmill terhadap denyut nadi istirahat. Hal ini dapat dibuktikan dari analisis data tes terakhir dimana nilai " $t$ " hitung yang diproleh lebih besar dibandingkan nilai " $t$ " tabel pada taraf kepercayaan 0,05 dan derajat kebebasan (n-1) 12. 
Sport Science: Jurnal Sain Olahraga dan Pendidikan Jasmani ISSN 114-562X (Cetak), ISSN XXXX-XXXX(Online)

http://sportscience.ppj.unp.ac.id/index.php/jss/index

Latihan merupakan faktor yang sangat penting dalam peningkatan kekuatan otot, sedangkan kekuatan otot merupakan modal untuk mempermudah mempelajari teknik, mencegah terjadinya cidera dan mencapai prestasi maksimal. Latihan fisik atau olahraga berpengaruh baik terhadap fungsi jantung. Mengingat program latihan jogging sangat penting dalam menjalankan aktivitas latihan hendaknya perlu diperhatikan dalam realisasi di lapangan atau di ruang fitness, karena dengan berlatih jogging yang teratur akan diperoleh beberapa keuntungan dari orang yang melaksanakannya. Apabila olahraga dilakukan sesuai prinsip-prinsip dasarnya, maka akan dapat meningkatkan kualitas fisik, sehingga terjadi efisiensi fungsional dan optimal. Peningkatan ini menimbulkan perubahan terhadap system kardiovaskuler dan perubahan lain.

Disamping itu peranan penting juga dipegang oleh instruktur yang mengajar di fitness centre, karena latar belakang dari ilmu yang diperoleh melalui fitness centre tersebut serta pengalamanpengalaman instruktur dalam memberikan latihan jogging dengan treadmill sangatlah dibutuhkan dalam mencapai tujuan yang dikehendaki bersama, yakni terjadinya penurunan denyut nadi istirahat.

Pada sisi lain tentu saja ibu-ibu juga memegang peranan penting dalam penelitian ini dengan keaktifan ibu-ibu ini sendiri. Maksud keaktifan disini adalah ibu-ibu tersebut berlatih secara kontiniu, tanpa menimbulkan rasa kelelahan dalam mengikuti kegiatan latihan jogging dengan treadmill. Treadmill merupakan salah satu alat untuk mengukur tes kebugaran jasmani, dengan pengukuran denyut nadi maksimal yaitu 220 - usia dari hasil denyut nadi maksimal. Untuk mencapai zona latihan, maka intensitas latihannya $70 \%$ sampai $85 \%$ dari denyut nadi maksimal, durasi $30-40$ menit dan frekuensi latihan 3 kali dalam seminggu.

Dengan demikian jelaslah bahwa program latihan yang dijalankan dalam latihan jogging dengan treadmill sangat berpengaruh terhadap penurunan denyut nadi istirahat. Dengan adanya penurunan denyut nadi istirahat merupakan salah satu ukuran tingkat kesegaran jasmani seseorang. Kiranya harapan inilah yang didambakan oleh ibu-ibu anggota fitness centre Yayasan Jantung Indonesia Cabang Utama Sumatera Barat untuk menjalani kehidupan yang segar dan sehat sehariharinya. Sehingga keluhan-keluhan yang dirasakan bukanlah mimpi buruk lagi, namun telah dapat teratasi melalui penelitian yang sederhana ini.

\section{KESIMPULAN}

Berdasrkan analisis data yang telah dilakukan dalam pembahasan dapat disimpulkan bahwa latihan jogging dengan treadmill intensitas $70 \%$ - 85\% dapat meningkatkan efisiensi kerja jantung yang dapat dilihat pada penurunan denyut nadi istirahat. Perbedaan yang berarti antara tes awal dan tes akhir terhadap denyut nadi istirahat pada ibu-ibu anggota Fitness Centre Yayasan Jantung Indonesia Cabang Utama Sumatera Barat.

Berhubungan secara empiris telah terbukti bahwa latihan jogging dengan treadmill, diyakini sebagai upaya latihan jogging yang lebih baik dalam pencapaian hasil denyut nadi. Berikut ini di kemukakan saran-saran untuk dapat dipertimbangkan; Disarankan pada ibu-ibu agar dapat melakukan latihan jogging secara teratur dan kontiniu, karena latihan jogging itu dapat meningkatkan efisiensi kerja jantung yang dilihat dengan penurunan denyut nadi istirahat.

Berdasarkan penelitian, dimana latihan jogging dapat meningkatkan kebugaran jasmani, maka disarankan kepada ibu-ibu anggota fitness centre agar dapat memasyarakatkan latihan jogging dengan treadmill. Kepada instruktur agar dapat menjalankan latihan jogging dengan treadmill ini dalam proses yang sebenarnya untuk menurunkan denyut nadi istirahat. Kepada Yayasan Jantung Indonesia Cabang Utama Sumatera Barat, agar lebih mengembangkan latihan jogging dengan treadmill dalam proses sebenarnya yang diprioritaskan pada klub Jantung Indonesia bagi ibu-ibu, bapak-bapak dan remaja. Kepada peneliti berikutnya agar dapat mengadakan penelitian lanjutan dengan menggunakan sampel yang lebih banyak dan waktu yang lebih lama. 


\section{Sport Science: Jurnal Sain Olahraga dan Pendidikan Jasmani ISSN 114-562X (Cetak), ISSN XXXX-XXXX(Online) http://sportscience.ppj.unp.ac.id/index.php/jss/index}

\section{DAFTAR RUJUKAN}

Arikunto, Suharsimi.1998. Metode Penelitian. Jakarta: Bumi Aksara

Bafirman. 1999. Diktat Sport Medicine. Padang : IKIP Padang 2006. Fisiologi Olahraga. Padang: Fakultas Ilmu Keolahragaan UNP

Dinata, Marta. 2005. Lari Jarak Jauh. Jakarta: Penerbit Cerdas Jaya

Cooper. 1977. Aerobik. Jakarta : PT. Gramedia

Fox. El. Bowers Rw. Fosa MI. 1988. The Physiological Basic Of Physical Education and Athletich. $4^{\text {th }}$ Edition. Philadelphia: Saunders College

.1993. The Physiological Basic For Exercise and Sport. Dobuque : Wm.C. Brown Comunications, Inc

Guyton. 1991. Fisiologi Manusia dan Mekanisme Penyakit. Jakarta: Buku Kedokteran EGC

Hairy, Junusul. 1989. Fisiologi Olahraga. Jakarta: Departemen P dan K

Irwansyah. 2008. Pengaruh Latihan Senam Aerobik Low Impact Terhadap Denyut Nadi Istirahat dan Masa Pemulihan (Recovery) pada Ibu-ibu anggota fitness Centre Dua Dara di Bangko. (skripsi). Padang: FIK - UNP

Jansen G.j. M Peter. 1993. Latihan Laktat Denyut Nadi. Jakarta: Percetakan PT. Temprint

Jhonson BL, Nelson Jk. 1986. Practical Measurements for Evalution In Physical Education. $4^{\text {th }}$ Edition, New York : Macmilan Publishing Company

Kusuma. 1997. Olahraga Bagi Kesehatan Jantung. Jakarta: Fakultas Kedokteran Universitas Indonesia

Mary, Moore Courtney. 1997. Buku pedoman Terapi Diet dan Nutrisi. Jakarta : Hipokrates

Nangsari, Nyanyu Sam. 1988. Pengantar Fisiologi Manusia. Jakarta: Departemen P dan K

Nawawi, Umar. 2006. Fisiologi. Padang: FIK - UNP

Radioputro. 1979. Fisiologi Olahraga. Yogyakarta: Yayasan Sekolah Tinggi Olahraga

Saputra, Prayoga Jaya. 2001. Pengaruh Senam Aerobik Low Impact terhadap Efisiensi Kerja Jantung Ibu-ibu di Fitnes Centre FIK Lubuk Buaya. (skripsi). Padang: FIK - UNP

Soekarman, R. 1991. Buku Tek Ilmu Faal V. Bandung: UNAIR

Sudjana. 1992. Metode Statistika. Bandung: Tarsito

Sumasardjono, Sadoso. 1990. Pengetahuan Praktis Kesehatan Dalam Olahraga 2. Jakarta: PT Gramedia Utama . 1996. Sehat Dan Bugar. Jakarta: PT Gramedia Utama

Supardi. 1998. Pengaruh Latihan Naik Turun Bangku Satu Tingkat dan Naik Bangku Dua Tingkat Terhadap Denyut Nadi Maksimal Serta Kekuatan Otot Tungkai. Surabaya: IKS - UNAIR 
Sport Science: Jurnal Sain Olahraga dan Pendidikan Jasmani

ISSN 114-562X (Cetak),

ISSN XXXX-XXXX(Online)

http://sportscience.ppj.unp.ac.id/index.php/jss/index

. 1999. Job Sheet Pratikum Sport Medicine. Padang: Fakultas Ilmu Keolahragaan

. 2006. Sport Science. Padang: FIK- UNP

menggunakan aplikasi Reference Manager, seperti Zotero, Mendeley, atau aplikasi yang lain. Ditulis dalam spasi tunggal, antar daftar pustaka diberi jarak 1 spasi. Sebagian contoh cara penulisan referensi/acuan di dalam Daftar Pustaka,diberikan berikut.

Gronlund, N.E. \& Linn, R.L. (2105). Measurement and evaluation in teaching. (6 ${ }^{\text {th }}$ ed.). New York: Macmillan.

Effendi,S. (2014). Unsur-unsur penelitian ilmiah. Dalam Masri Singarimbun (Ed.). Metode penelitian survei. Jakarta: LP3ES.

Pritchard, P.E. (2012). Studies on the bread-improving mechanism of fungal alpha-amylase. Journal of Biological Education, 26 (1), 14-17.

Retnawati, H. (2014). Teori respon butir dan penerapannya. Yogyakarta: Nuha Medika.

Prasetyo, D., \&Sukarmin, Y. (2017).Pengembangan model permainanuntukpembelajaranteknikdasar bola basket di SMP. JurnalKeolahragaan, 5(1), 12-23. doi:http://dx.doi.org/10.21831/jk.v5i1.12758 